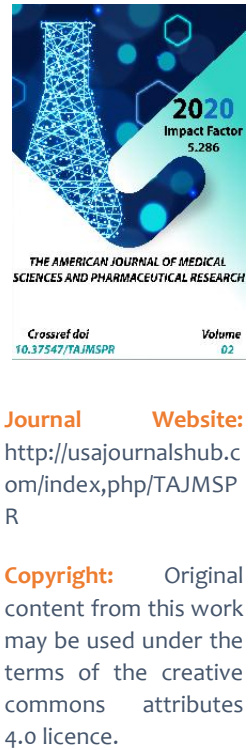

\title{
Anesthesia For Total Arthroplasty Of The Joints Of The Lower Extremities In Patients With A High Anesthetic Risk
}

\author{
Gaziev Z.T.
}

Tashkent Medical Academy, Uzbekistan

Avakov V.E.

Tashkent Medical Academy, Uzbekistan

\section{ABSTRACT}

Purpose: to determine the effect of unilateral spinal anesthesia on systemic and central hemodynamics, to identify its side effects in the elderly and senile, with total hip replacement.

Materials and methods: 60 patients of geriatric age operated on under unilateral spinal anesthesia were examined. 44 patients underwent total hip arthroplasty (THA), 16 - total knee arthroplasty (TKA). Inclusion criteria: elderly (from 60 to 75 years). For continuous monitoring of the vital functions of the patient, they used the "resuscitation and surgical" monitor UM 300 (LLC UTAS Company Ukraine).

Conclusion: Unilateral spinal anesthesia is a safe and highly effective technique that can provide full intraoperative pain management for patients with total hip replacement in a high-risk group of patients.

\section{KEYWORDS}

Unilateral anesthesia, spinal anesthesia, joint replacement of the lower limb. 


\section{INTRODUCTION}

Of all types of arthroplasty, hip replacement surgery is most often performed, which in patients of this age group is most often accompanied by the use of bone cements due to osteoporosis, the need for early activation in the postoperative period, or due to the developed aseptic instability of the endoprosthesis components $(9,7)$.

To date, it is considered an established fact of the progressive aging of the population with an increase in the number of "storage diseases" requiring surgical treatment, which include a violation of the morphology and function of the musculoskeletal system $(2,3)$. Often people over 65 are forced to maintain their ability to work and lead an active lifestyle.

In elderly patients, this intervention is performed practically for health reasons, since conservative treatment leads to deaths in $80 \%$ of cases due to hypostatic complications $(1,6)$. Thus, safe and effective endoprosthetics is acquiring not only clinical but also social significance.

The safety and effectiveness of anesthetic management of this highly traumatic intervention seems to be a difficult task, given the mechanisms of its negative impact on the homeostasis of the elderly, which have fatal coincidences with some pathophysiological manifestations of aging, which increases the risk of surgery and anesthesia $(4,5)$. First of all, this concerns the aggravation of the initial incompetence of central and peripheral hemodynamics, deficiency of circulating blood volume (CBV), catabolic direction of metabolism, tendency to thrombotic complications, and gas exchange disorders (8).
Purpose: to assess the effect of unilateral spinal anesthesia on systemic and central hemodynamics, to identify its side effects in patients with high anesthetic risk.

\section{MATERIAL AND METHODS}

The study is based on the results of examination of 63 patients who were treated in the department of orthopedics of large joints and hands of the multidisciplinary clinic of the Tashkent Medical Academy, who underwent primary arthroplasty of the joints of the lower extremities. Examined 63 patients of geriatric age, operated under conditions of combined spinal-epidural anesthesia. 44 patients underwent total hip arthroplasty (THA), 16 - total knee arthroplasty (TKA). Inclusion criteria: elderly (from 60 to 75 years old), pain syndrome for more than one year, no contraindications for regional methods of anesthesia, severe (grade 3 or 4 ) ostearthrosis (according to KellgrenZawrenee, 1957), resistant to conservative methods of treatment; Body mass index $<40 \mathrm{~kg} / \mathrm{m} 2$; In $31.5 \%$ of the examined patients, physical status was assessed as class 1-2 according to ASA, in $68.5 \%$ of patients it corresponded to class 3-4.

The exclusion criteria from the study were: patient refusal from this type of pain relief, age less than 60 years, body weight less than $50 \mathrm{~kg}$, history of allergic reactions to local anesthetics used, coagulopathy, neurological and neuromuscular diseases, severe liver disease, renal failure, the inability to cooperate with the patient.

The patients were diagnosed with from 2 to 6 concomitant diseases, among which IHD with chronic circulatory failure, atherosclerotic 
cardiosclerosis, hypertension of the 2nd degree with a high risk of cardiovascular and respiratory complications, arrhythmias prevailed. For continuous monitoring of the vital functions of the patient, we used the "resuscitation-surgical" monitor YUM 300 (LLC “Company UTAS” Ukraine).

The technique of unilateral (unilateral) spinal anesthesia to the patient in a lateral position (operated leg at the bottom) was performed with aseptic and antiseptic dural puncture with a Quincke 25-gauge needle (Spinocan, Brown, Germany) along the midline at the L3L4 level. After the intrathecal puncture, the needle hole was turned downward (towards the operated lower limb) and $7.5 \mathrm{mg}$ of a $0.5 \%$ hyperbaric solution of bupivacaine was injected for 60-80 seconds.

Results and discussion:

Table \# 1. Demographic indicators and patient comorbidity index $(n=60)$

\begin{tabular}{|c|c|c|c|c|}
\hline \multicolumn{2}{|c|}{ Indicators } & Number of & $\%$ & Unilateral anesthesia \\
\hline \multirow{3}{*}{ Age / years } & $\begin{array}{l}\text { Group } \\
\text { average }\end{array}$ & & & $75,8 \pm 3,9$ \\
\hline & $64-75$ & 39 & 61,9 & $72,3 \pm 2,5$ \\
\hline & 76-87 & 24 & 38,1 & $79,3 \pm 1,4$ \\
\hline \multicolumn{2}{|l|}{ Sex m / f } & & & $28 / 34$ \\
\hline \multicolumn{2}{|l|}{$\mathrm{BMI}(\mathrm{kg} / \mathrm{m} 2)$} & & & $28,2 / 3,1$ \\
\hline \multicolumn{2}{|l|}{ Operation side $\mathrm{r} / \mathrm{l}$} & & & $28 / 3,5$ \\
\hline \multirow{3}{*}{$\begin{array}{l}\text { Charlson } \\
\text { Comorbidity Index }\end{array}$} & До 2 & 20 & $(31,7 \%)$ & \\
\hline & До 3 & 20 & $(31,7 \%)$ & \\
\hline & $\geqslant 4$ & 23 & $(36,5 \%$ & \\
\hline
\end{tabular}

The average age was $75.8 \pm 3.9$ years, about $40 \%$ of patients were elderly, as evidenced by
The lateral positions of the patients were maintained for 15-20 minutes, then they were transferred to the supine position with a raised head end. The dose of intrathecal administered hyperbaric $0.5 \%$ bipivacaine 7.5 $\mathrm{mg}$ for unilateral spinal anesthesia was deliberately chosen by us as the most frequently recommended dose without a combination with intrathecal administration of fentanyl (sufentanil), and also taking into account the fact that there are studies in the literature indicating that a decrease in the local anesthetic dose increases the incidence of failed unilateral spinal anesthesia) after intrathecal administration of $4 \mathrm{mg}$ and $6 \mathrm{mg}$ of hyperbaric bupivacaine. 
Doi: https://doi.org/10.37547/TAJMSPR/Volume02Issue09-12

the Charlson comorbidity index (36.5\%).

Height-weight BMI also indicated normotrophy.

Among the comorbidities in this group of patients dominated: atherosclerotic changes, essential hypertension, coranarocardiosclerosis, coronary artery disease with circulatory insufficiency of II-III class according to NYHA, COPD arrhythmias, pneumosclerosis, pulmonary emphysema, respiratory failure, varicose veins of the lower extremities, hormonal disorders, cerebrovascular accidents, diabetes.

The table below shows the values (mean) of systemic hemodynamics and pulse oximetry in patients operated on under the conditions of the USA.

Table 2 Indicators of systemic hemodynamics and SpO2 before and at the stages of USA $(n=6)$

\begin{tabular}{|c|c|c|c|c|c|c|c|}
\hline \multirow[t]{2}{*}{ Indicators } & \multicolumn{7}{|c|}{ Stages of the operation and the postoperative period } \\
\hline & Result & $\begin{array}{l}\text { Start of } \\
\text { operation }\end{array}$ & $\begin{array}{l}\text { Joint } \\
\text { implant }\end{array}$ & $\begin{array}{l}\text { End of } \\
\text { operation }\end{array}$ & $\begin{array}{l}30 \\
\text { minutes }\end{array}$ & $\begin{array}{l}60 \\
\text { minutes }\end{array}$ & $\begin{array}{l}120 \\
\text { minutes }\end{array}$ \\
\hline $\begin{array}{l}\text { Syst blood } \\
\text { pressure }\end{array}$ & $142,9 \pm 3,7$ & $136,0 \pm 3,9$ & $\begin{array}{l}134,2 \quad \pm \\
2,7^{\mathrm{x}}\end{array}$ & $136,7 \pm 4,2$ & $\begin{array}{l}139,9 \pm \\
3,4\end{array}$ & $\begin{array}{l}137,5 \pm \\
4,1\end{array}$ & $\begin{array}{l}138,4 \quad \pm \\
3,6\end{array}$ \\
\hline $\begin{array}{l}\text { Diastol blood } \\
\text { pressure }\end{array}$ & $92,4 \pm 3,6$ & $88,4 \pm 2,8$ & $89,1 \pm 3,4$ & $86,3 \pm 4,0$ & $\begin{array}{l}87,0 \quad \pm \\
3,7\end{array}$ & $\begin{array}{l}86,4 \quad \pm \\
3,3\end{array}$ & $\begin{array}{l}84,0 \quad \pm \\
3,0\end{array}$ \\
\hline $\begin{array}{l}\text { Systemic } \\
\text { blood } \\
\text { pressure }\end{array}$ & $109,2 \pm 7,4$ & $104,2 \pm 3,9$ & $\begin{array}{l}104,1 \quad \pm \\
4,1^{\mathrm{xx}}\end{array}$ & $103,1 \pm 3,7$ & $\begin{array}{l}104,6 \pm \\
4,2\end{array}$ & $\begin{array}{l}103,4 \pm \\
3,7\end{array}$ & $\begin{array}{l}102,1 \quad \pm \\
3,5\end{array}$ \\
\hline $\mathrm{HR}$, per min & $69,4 \pm 2,9$ & $65,7 \pm 2,7$ & $64,8 \pm 3,0$ & $65,4 \pm 2,9$ & $\begin{array}{l}68,2 \quad \pm \\
3,1\end{array}$ & $\begin{array}{l}65,2 \quad \pm \\
2,2\end{array}$ & $\begin{array}{l}65,7 \quad \pm \\
2,0\end{array}$ \\
\hline $\begin{array}{l}\text { CVP, } \quad \mathrm{mm} \\
\mathrm{H} 20\end{array}$ & $7,6 \pm 0,4$ & $7,4 \pm 0,3$ & $8,1 \pm 0,4^{\mathrm{x}}$ & $8,3 \pm 0,3$ & $\begin{array}{ll}8,8 & \pm \\
0,5 & \end{array}$ & $\begin{array}{ll}8,1 \quad \pm \\
0,6\end{array}$ & $\begin{array}{ll}8,2 & \pm \\
0,4 & \end{array}$ \\
\hline $\mathrm{SpO}_{2}, \%$ & $90,1 \pm 0,4$ & $92,3 \pm 0,5$ & $91,7 \pm 0,6$ & $92,2 \pm 0,5$ & $\begin{array}{l}91,2 \quad \pm \\
0,4\end{array}$ & $\begin{array}{l}91,3 \quad \pm \\
0,3\end{array}$ & $\begin{array}{ll}91,7 \quad \pm \\
0,4\end{array}$ \\
\hline
\end{tabular}

Note: $x-p<0.05$ relative to the initial values

The averaged values characterize the USA as an anesthesia with fairly stable hemodynamic characteristics. We drew attention to the fact that blood pressure at the most traumatic stage of the operation was the lowest relative to all other stages of the study. So, if by the beginning of the operation systolic blood pressure was lower than the initial data by 
Doi: https://doi.org/10.37547/TAJMSPR/Volume02Issue09-12

$4.9 \%(p>0.05)$, then at the stage of joint implantation this difference was $6.1 \%$ ( $p$ $<0.05)$. As for diastolic blood pressure and systolic blood pressure, they were remarkably stable at all stages of the operation. The same can be said about CVP and $\mathrm{SpO}_{2}$ indicators. As for the heart rate, at the beginning of the operation and by the time of joint implantation, it noted a tendency to decrease, but later it was at the level of age characteristics.

With a more detailed analysis of the period of the USA (injection of anesthetic) and before the operation and implantation of joint components, the dynamics of blood pressure and systolic blood pressure was as follows

Table 3. Values of blood pressure and systemic blood pressure during the period of USA and before the start of the operation

\begin{tabular}{|l|l|l|l|}
\hline Time, $\min$ & Systilic BP & Diastolic BP & Systemic BP \\
\hline 0 mins & $142,9 \pm 3,7$ & $92,4 \pm 3,6$ & $109,2 \pm 4,7$ \\
\hline 5 mins & $121,7 \pm 2,4^{\mathrm{x}}$ & $70,4 \pm 2,4^{\mathrm{x}}$ & $87,4 \pm 2,5^{\mathrm{x}}$ \\
\hline 10 mins & $123,5 \pm 3,1^{\mathrm{x}}$ & $71,2 \pm 2,7^{\mathrm{x}}$ & $88,8 \pm 2,9^{\mathrm{x}}$ \\
\hline 15 mins & $118,9 \pm 2,7^{\mathrm{x}}$ & $70,9 \pm 2,9^{\mathrm{x}}$ & $86,9 \pm 1,7^{\mathrm{x}}$ \\
\hline 20 mins & $121,6 \pm 2,4^{\mathrm{x}}$ & $71,0 \pm 2,8^{\mathrm{x}}$ & $87,8 \pm 2,1^{\mathrm{x}}$ \\
\hline 25 mins & $129,7 \pm 2,8^{\mathrm{x}}$ & $78,8 \pm 2,7^{\mathrm{x}}$ & $95,7 \pm 2,6^{\mathrm{x}}$ \\
\hline $30 \mathrm{mins}$ & $136,0 \pm 3,9$ & $88,4 \pm 2,8$ & $104,2 \pm 3,9$ \\
\hline $60 \mathrm{mins}$ & $135,1 \pm 3,2$ & $86,2 \pm 3,9$ & $102,5 \pm 3,4$ \\
\hline 90 mins & $134,2 \pm 2,7$ & $84,2 \pm 2,8$ & $101,0 \pm 2,1$ \\
\hline 110 mins & $135,9 \pm 3,3$ & $85,1 \pm 2,3$ & $102 \pm 2,8$ \\
\hline 120 mins & $136,7 \pm 4,2$ & $84,9 \pm 3,1$ & $102,1 \pm 2,5$ \\
\hline
\end{tabular}

Note: $\mathrm{x}-\mathrm{p}<0.05$ relative to 0 minutes

The presented data indicate significant hemodynamic shifts for the first time 25 minutes of USA. The most rapidly decreased systolic, diastolic blood pressure and systemic blood pressure in the first 5 minutes by $14.9 \%$ ( $p<0.05), 24.1 \%$ and 20\% (p <0.05), respectively. The most significant changes in these indicators were noted at the 15th minute of the study (by $16.8 \%, 23.3 \%$ and $20.5 \%$, respectively). From the 30-40th minute, they all relatively stabilized, which made it possible to begin surgery. During the reoperative period, 2 patients had severe bradycardia up to 47 and 49 beats per minute, which was quickly corrected by the introduction of 0.5 mg of atropine. No cardiovascular complications were observed in the postoperative period. 
Below are the indicators of $\mathrm{CH}$ in patients of this group, operated under conditions of the USA.

These indicators fit into the hypodynamic regime of blood circulation. Interesting, in our opinion, was the fact that with a decrease in blood pressure and systemic blood pressure at the stages of the beginning of the operation and implantation of the joint, it occurs not

Table 4. Indicators of $\mathrm{CH}$ at the early stages of surgery in patients, depending on the elderly and senile age.

\begin{tabular}{|c|c|c|c|c|c|}
\hline \multirow[b]{2}{*}{ Indicators } & \multirow[b]{2}{*}{ Age } & \multirow{2}{*}{$\begin{array}{l}\text { Number of } \\
\text { patients }\end{array}$} & \multicolumn{3}{|c|}{ Stages of operation } \\
\hline & & & Result & Beginning & $\begin{array}{l}\text { Implant of } \\
\text { the joint }\end{array}$ \\
\hline \multirow{2}{*}{$\begin{array}{l}\text { Impact index, } \\
\mathrm{ml} / \mathrm{m}^{2}\end{array}$} & $65-75$ & 29 & $24,0 \pm 0,6$ & $23,2 \pm 0,4$ & $24,6 \pm 0,2^{x}$ \\
\hline & $76-92$ & 31 & $19,9 \pm 0,8$ & $17,4 \pm 0,6^{x}$ & $15,8 \pm 0,2^{x}$ \\
\hline \multirow{2}{*}{ Heart index, $1 / \mathrm{m}^{2}$} & $65-75$ & 29 & $1,74 \pm 0,03$ & $1,69 \pm 0,02$ & $1,57 \pm 0,03^{x}$ \\
\hline & $76-92$ & 31 & $1,32 \pm 0,05$ & $1,23 \pm 0,03$ & $0,91 \pm 0,04^{\mathrm{x}}$ \\
\hline \multirow{2}{*}{ TPVR,dyn* $\mathrm{cm}^{-5}$} & $65-75$ & 29 & $2904,3 \pm 98,0$ & $3280,3 \pm 154,9^{x}$ & $\begin{array}{l}3519,7 \pm 121,9 \\
x\end{array}$ \\
\hline & $76-92$ & 31 & $3449,1 \pm 82,1$ & $3693,7 \pm 79,7^{x}$ & $\begin{array}{l}3649,3 \pm 170,7 \\
x\end{array}$ \\
\hline
\end{tabular}

Note: $x-p<0.05$ relative to the age indicator

The data presented again demonstrate a significant difference in $\mathrm{CH}$ indicators in the early stages of surgery, depending on age and comorbidity. So, if in patients aged $65-75$ years the $\mathrm{SI}$ decreases by $5.9 \%$ ( $\mathrm{p}<0.05)$ by the III stage of the study, then the streets $76-92$ years old by $20.6 \%(p<0.05)$. SI at the same stage of the research stage was $9.8 \%$ and $31.1 \%$, respectively. As for the TPVR, it increased in patients $65-75$ years of age by the beginning of the operation by $12.9 \%$, and by the III stage by $21.2 \%(p<0.05)$, this is the same indicator in only due to the sympathetic block caused by a local anesthetic, but also due to a decrease in the one-time and minute productivity of the heart. But it was interesting that with a decrease in the indicators of systemic and central hemodynamics, there is a statistically significant increase in TPVR. 
TPVR, averaging $3734.5 \pm 146.3$ dyn.cm-5, values (3408.1 dyn.cm-5). turned out to be $8.8 \%$ higher than the proper

Table No. 5. The volume of surgical blood loss, ITT and time parameters in patients operated on under the conditions of the USA $(n=60)$.

\begin{tabular}{|l|l|}
\hline Indicators & Values \\
\hline Blood loss, ml & $502,7 \pm 30,6$ \\
\hline THA & $484,3 \pm 24,9$ \\
\hline TKA & $521,1 \pm 35,8$ \\
\hline ITT volume, ml & $2019,9 \pm 290,6$ \\
\hline Erythrocyte mass, ml & $196,9 \pm 40,4$ \\
\hline Time before the start of the operation, min & $51,7 \pm 6,7$ \\
\hline Operation time, min & $121,8 \pm 6,9$ \\
\hline Time spent in the operating room after surgery, min & $23,7 \pm 2,9$ \\
\hline The duration of the application of the tourniquet, min $(\mathrm{n}=4)$ & $88,3 \pm 2,7$ \\
\hline Recovery time of cognitive functions, min & $16,8 \pm 1,7$ \\
\hline
\end{tabular}

The total blood loss in this group of patients was $7 \mathrm{mg} / \mathrm{kg}$, with THA - $6.5 \mathrm{ml} / \mathrm{kg}$, with TKA $-7-8 \mathrm{ml} / \mathrm{kg}$. The infusion volume in this group was $26.9 \mathrm{ml} / \mathrm{kg}$, the volume of erythromass transfused $-3.28 \mathrm{ml} / \mathrm{kg}$.

The recovery time of cognitive functions was usually restored quickly within 15-20 minutes.

Complications in patients: Deep vein thrombosis of the operated limb (1 patient), rhythm disturbance: paroxysmal tachycardia (2), bradyarrhythmia - (2) atrial fibrillation - (3), congestive pneumonia - (2), respiratory depression - (2), nausea, vomiting (4), urinary retention (3). The frequency of moderate hypotension in the range of $15-19 \%$ relative to the values in the reoperative period of this group of patients was $12.3 \%$.

\section{CONCLUSIONS}

1. Unilateral spinal anesthesia is a safe and highly effective technique that can provide full intraoperative pain relief for patients with total hip arthroplasty in a high-risk group of patients.

2. The use of unilateral spinal anesthesia provides sufficient hemodynamic stability in older patients.

3. The number of intraoperative complications among patients who underwent unilateral spinal anesthesia is significantly less than with the classical SA technique. 


\section{REFERENCES}

1. Bastrikin S.Yu. Regional anesthesia in traumatology and orthopedics / S.Yu. Bastrikin, A.M. Ovechkin, N.M. Fedorovsky. Regional anesthesia and pain management: thematic. Sat. / ed. A. M. Ovechkina, S. I. Sitkin. Tver, 2004: 239-246.

2. Bessonov S.V. Features of anesthetic support of endoprosthetics of large joints of the lower extremities / S.V. Bessonov, A.K. Orletskiy, V.A. Kassil. Vestn. traumatology and orthopedics them. N.N. Priorov. 2005; 1: 85-90.

3. Dadaev M.Kh. Total arthroplasty of the hip joint with endoprostheses with cementless fixation of components in case of fracture of the femoral neck in elderly and senile people: dis,... cand. Honey. Science / M.Kh. Dadaev; RMAPO. - M., 2006 .-- 124 s.

4. Koryachkin V.A., Chupris V.G., Cherny A.Zh., Kazarin V.S., Liskov M.A., Malevich G.M., Maltsev M.P. Systemic toxicity of local anesthetics in regional anesthesia in orthopedics and traumatology. Traumatology and Orthopedics of Russia. 2015; No. 1 (75): 129-135.

5. Ovechkin AM, Politov ME, Panov NV Anesthetic management of total arthroplasty of the joints of the lower extremities - which method should be preferred? Anesthesiology and Critical Care Medicine No. 6 (135), 2017 p6-11

6. Eroglu A. Comparison of hypotensive epidural anesthesia and hypotensive total intravenous anesthesia on intraoperative blood loss during total hip replacement / A. Eroglu, H. Uzunlar, N. Erciyes. J. Clin. Anesth. 2005 Sep .; 17 (6): 420-425.

7. Mauerman W.J. Comparison of Neuraxial Block Versus General Anesthesia for Elective Total Hip Replacement: A Meta-
Analysis / W.J. Mauermann, A.M. Shilling, Z.A. Zuo. Anesth Analg. 2006; 103: 10181025.

8. Memtsoudis SG, Rasul R, Suzuki S, Poeran J, Danninger T, Wu C, et. al. Does the impact of the type of anesthesia on outcomes differ by patient age and comorbidity burden? Reg anesth Pain Med 2014; 39: 112-9

9. Richman J.M. Does neuraxial anesthesia reduce intraoperative blood loss: a metaanalysis.? / J.M. Richman, [et al.]. J. Clin. Anesth. 2006418 (6): 427-435. 